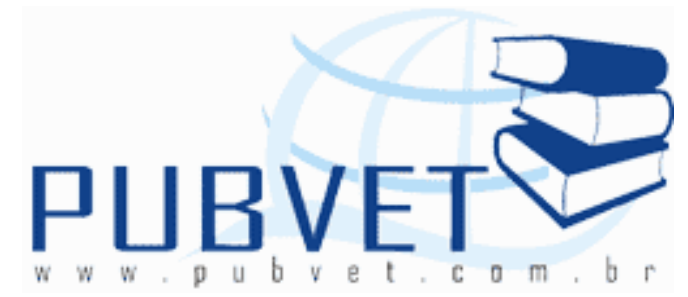

PUBVET, Publicações em Medicina Veterinária e Zootecnia.

\title{
Aditivos alternativos na alimentação de aves
}

\section{Maryelle Durães de Oliveira ${ }^{1}$; Kelen Cristiane Zavarize ${ }^{2}$; Natali Almeida \\ Gomes$^{2}$; Fernanda Rodrigues Taveira Rocha²; Julyana Machado da Silva Martins $^{3}$; Fernanda Heloisa Litz $^{3}$; Henrique Castilhano ${ }^{4}$}

${ }^{1}$ Zootecnista bolsista de apoio técnico na Universidade Federal de Goiás

2 Docentes da Universidade Estadual de Goiás

${ }^{3}$ Alunas da pós-graduação em Ciências Veterinárias -FAMEV-UFU

${ }^{4}$ Zootecnista autônomo

\section{Resumo}

Existe a preocupação com o uso contínuo e indiscriminado de antibióticos na alimentação de aves no sentido dessas substâncias exercerem risco, tanto para a saúde animal quanto humana, pois estes podem causar resistência aos microrganismos patogênicos, além de deixar resíduos em produtos de origem animal, o que é de preocupação para segurança alimentar do consumidor. Dessa forma devido a exigência do mercado consumidor por produtos de qualidade levaram a restrição aos antibióticos administrados na alimentação de aves e as buscas por alternativas como probióticos, prebióticos, simbióticos e aditivos fitogênicos, por proporcionarem condições favoráveis ao desenvolvimento de microrganismos benéficos ao trato gastrointestinal e diminuição do estresse imunológico. Portanto, o presente estudo teve como 
OLIVEIRA, M.D. et al. Aditivos alternativos na alimentação de aves. PUBVET, Londrina, V. 6, N. 27, Ed. 214, Art. 1425, 2012.

objetivo relatar o efeito dos aditivos alternativos (probióticos, prebióticos, simbióticos e aditivos fitogênicos) na dieta de aves.

Palavras-chave: Avicultura, Imunidade, Morfologia Intestinal, Nutrição, Promotores de crescimento.

\section{Alternative feed additives in poultry}

\section{Abstract}

A possible bacterial pathogens resistant dissemination due to presence of medication residues in animal origin products and consumer market demand for quality products led to restriction on antibiotics administered in chicken feed, and the search for alternatives such as probiotics, prebiotics, symbiotic and phytogenic additives by offering favorable conditions to beneficial microorganisms to gastrointestinal tract development, immune stress reduction. Therefore, the objective of this study was to report alternative additives effect (probiotics, prebiotics, and synbiotics phytogenic additives) in poutry diet.

Keywords: Growth Promoter, Immunity, Intestinal Morphology, Nutrition, Poutry.

\section{INTRODUÇÃO}

Pesquisas relacionadas à nutrição de aves são consideradas importantes, devido às constantes melhorias genéticas e a aplicação de tecnologias que ocorrem nesse setor de produção. O rápido e adequado ganho de peso das aves está diretamente relacionado à nutrição, sendo assim, necessária a adoção de critérios nutricionais que mantenham a saúde do organismo das aves, especialmente a saúde intestinal para se obter melhor desempenho.

Considerando a saúde intestinal e a ótima eficiência zootécnica do animal, uma ferramenta importante é a utilização de aditivos na dieta. Aplicase a esse termo aditivo para as substâncias, as quais quando adicionadas às 
OLIVEIRA, M.D. et al. Aditivos alternativos na alimentação de aves. PUBVET, Londrina, V. 6, N. 27, Ed. 214, Art. 1425, 2012.

rações são capazes de melhorar o desempenho do animal e a qualidade física dos alimentos (SILVA, 2000; ARAúJO et al., 2007).

Entre os diversos tipos de aditivos incluem-se os antibióticos (substâncias produzidas por leveduras, fungos ou bactérias benéficas que atuam contra bactérias maléficas); os quimioterápicos (substâncias adquiridas por síntese química com ação semelhante à dos antibióticos) (MENTEN e LODDI, 2003); outros compostos alternativos como os probióticos, prebióticos e aditivos fitogênicos que atuam como agentes tróficos e como equilibradores da mucosa intestinal, favorecendo o desenvolvimento de bactérias benéficas e reduzindo a colonização das espécies patogênicas (MAIORKA, 2004).

Os antibióticos são amplamente aplicados na avicultura, em doses subterapêuticas, gerando grandes benefícios na produção animal, principalmente por melhorar o ganho de peso, a conversão alimentar e reduzir a mortalidade (BUTOLO, 1999; DIONÍZIO et al., 2002; MENTEN e LODDI, 2003; FLEMMING, 2005; LORENÇON et al., 2007).

Porém existe a preocupação com o uso contínuo e indiscriminado desses antibióticos na alimentação animal no sentido dessas substâncias exercerem risco, tanto para a saúde humana quanto animal, devido à presença de resíduos em produtos de origem animal para o consumo, o que pode determinar o desenvolvimento e disseminação de bactérias resistentes e essa resistência ser transferida aos microrganismos patogênicos (MENTEN e LODDI, 2003; SILVA, 2008; MEDEIROS, 2008).Contudo, as restrições impostas pela União Européia a respeito da utilização de antibióticos e de proteínas de origem animal na alimentação das aves, alteraram de forma significativa o manejo nutricional imposto aos animais de produção.

A exigência do mercado importador, as campanhas de proibição de antimicrobianos em rações e a opinião pública têm prevalecido na restrição aos antibióticos fornecidos na alimentação animal, como promotores de crescimento, e diante da necessidade de manutenção e até mesmo do aumento dos níveis produtivos são necessárias alternativas para garantir esse 
OLIVEIRA, M.D. et al. Aditivos alternativos na alimentação de aves. PUBVET, Londrina, V. 6, N. 27, Ed. 214, Art. 1425, 2012.

desempenho do animal e ao mesmo tempo a segurança dos consumidores (ALBINO et al., 2007).

Dentre as alternativas ao uso dos antibióticos encontram-se os aditivos que são os probióticos, prebióticos, simbióticos e aditivos fitogênicos, que têm proporcionado condições favoráveis ao desenvolvimento de microrganismos benéficos do trato gastrintestinal. Estes funcionam como agentes tróficos, que atuam estimulando e acelerando o processo de mitose que ocorrem na região cripta-vilo, aumentando assim o número de células e por consequência o tamanho dos vilos e profundidade das criptas resultando em melhor digestão e absorção de nutrientes, além de melhorar a qualidade dos produtos finais, sem causar riscos ao consumidor (SANTOS et al., 2002; MACARI e FURLAN, 2005; ARAÚjo et al., 2007).

Assim, objetivou-se revisar sobre o efeito dos aditivos alternativos (probióticos, prebióticos, simbióticos e aditivos fitogênicos) na nutrição de aves.

\section{REVISÃO DA LITERATURA}

\subsection{Morfologia e Saúde Intestinal}

A saúde intestinal atualmente é objeto de grande estudo e atenção intensa da agroindústria avícola. O termo saúde intestinal está relacionado ao desenvolvimento e integridade da mucosa, além da relação com a composição da microbiota intestinal e da atuação do sistema imune (MURAROLLI, 2008).

A formação da microbiota das aves ocorre nos primeiros dias de vida, por onde passam por vários processos de adaptação, em busca de uma maior eficiência nos processos de digestão e absorção (CANALLI et al., 1996; MAIORKA, 2001). As alterações morfológicas que se mais evidenciam são o aumento no comprimento do intestino, altura e densidade dos vilos, número de enterócitos e das células caliciformes. Essas alterações proporcionaram um aumento na área de superfície de digestão e absorção (MURAROLLI, 2008). O 
OLIVEIRA, M.D. et al. Aditivos alternativos na alimentação de aves. PUBVET, Londrina, V. 6, N. 27, Ed. 214, Art. 1425, 2012.

comprimento dos vilos e da profundidade das criptas, utilizados para mensurar o desenvolvimento intestinal, também podem ser considerados como indicadores da saúde intestinal (KUZMUK et al., 2005).

Segundo MACARI e MAIORKA (2000), os processos de absorção são dependentes de mecanismos que ocorrem na mucosa intestinal. $O$ desenvolvimento da mucosa é estimulado por agentes tróficos, ou seja, aqueles que estimulam o processo mitótico na região cripta-vilo, como consequência, há o aumento do número de células e tamanho do vilo.

Dessa forma, um agente trófico determina um aumento na quantidade de DNA, pois aumenta o número de células. Hormônios e peptídeos têm ação trófica na mucosa intestinal, e o mesmo ocorre com os nutrientes presentes no lúmen intestinal. Vários agentes parecem ter ação trófica sobre a mucosa intestinal, dentre eles encontram-se: aminas biogênicas, aminoácidos (como glutamina), MOS (mananoligossacarideos) e FOS (frutoligossacarideos), prebióticos e probióticos (FURLAN et al., 2004).

Há dois eventos citológicos que ocorrem associados à renovação celular (proliferação e diferenciação das células totipotentes localizadas na cripta e ao longo dos vilos); e perda de células por descamação que ocorre naturalmente no ápice dos vilos. Em frangos essa renovação celular ocorre de 72 a 96 horas, o que correspondente a $10 \%$ do seu ciclo de vida (MAIORKA, 2001).

$O$ equilíbrio entre os processos (perda e proliferação celular) determina um turnover (proliferação - migração - extrusão) e garante a manutenção do número de células e da habilidade funcional do epitélio (MACARI et al., 1994).

MAIORKA (2001) e FURLAN et al. ( 2004) relatam que caso haja a ocorrência no aumento da taxa de proliferação (mitose) com ausência, diminuição ou manutenção da taxa de extrusão (perda celular) haverá aumento no número de células e, consequentemente, observará aumento na produção de células da cripta, e na profundidade de cripta.

Pode- se afirmar que segundo FURLAN et al. (2004) as células caliciformes presentes nos vilos e criptas, é de suma importância na manutenção e desenvolvimento do epitélio intestinal. Estas células são 
OLIVEIRA, M.D. et al. Aditivos alternativos na alimentação de aves. PUBVET, Londrina, V. 6, N. 27, Ed. 214, Art. 1425, 2012.

secretoras de muco e possui funções de proteger o epitélio intestinal durante o processo de digestão; proteção contra infecções (ao funcionar como barreira protetora impedindo o contato de microrganismos com células epiteliais. Deste modo as células caliciformes aumentam a produção de muco, caso ocorra alteração na dieta, ou o animal seja submetido ao jejum, pois estas situações podem acarretar diminuição na camada de muco e propiciar ação de bactérias e protozoários patogênicos que causam destruição da mucosa.

Alguns trabalhos mostram que os probióticos, prebióticos e simbióticos podem melhorar a integridade da mucosa intestinal, indicando assim um efeito trófico e consequentemente melhor desempenho das aves (MACARI e MAIORKA, 2000; SANTIN et al., 2001; LODDI, 2003; PELICANO, 2005).

FLEMMING (2005) relata que a suplementação com lactobacilos favorece a manutenção da integridade da mucosa intestinal e viabiliza a absorção intestinal das aves.

PELICANO et al. (2005) descrevem que aves suplementadas com prebióticos e probióticos apresentaram maior altura de vilo nos três segmentos (duodeno, jejuno e íleo) e maior comprimento de cripta apenas no duodeno e jejuno em relação ao tratamento controle. IJI et al. (2001) observaram maior altura de vilos apenas no jejuno e não evidenciaram diferença quanto a profundidade de cripta. MURAROLLI, (2008) conseguiu observar alguns efeitos tróficos na morfologia intestinal das aves ao adicionar os aditivos prebióticos e probióticos na dieta.

Entretanto alguns autores não têm encontrado diferenças significativas a respeito dos parâmetros morfológicos, como cita NUNES (2008), que não evidenciou efeito positivo sobre qualquer parâmetro morfológico que avaliou utilizando aditivos de crescimentos. Da mesma maneira ocorreu com RIBEIRO et al. (2007), que avaliaram a adição de prebióticos, probióticos e simbióticos em aves desafiadas com Salmonella enteritides e não obtiveram nenhuma diferença nos parâmetros de altura de vilos e profundidade de criptas. Outros autores também não encontraram resultados significativos positivamente em relação a altura do vilo, profundidade de cripta em aves submetidas a 
OLIVEIRA, M.D. et al. Aditivos alternativos na alimentação de aves. PUBVET, Londrina, V. 6, N. 27, Ed. 214, Art. 1425, 2012.

alimentação com prebióticos e probióticos (SANTIN et al., 2001; YANG et al., 2007).

\subsection{Sistema Imune das Aves}

O sistema imune protege o organismo do animal contra agentes estranhos, tais como bactérias e vírus e suas funções podem servir como indicadores de um positivo e ou negativo impacto na homeostasia do animal (QURESHI, 2002).

O bom funcionamento do sistema imune reflete diretamente na produção de aves e nos altos desempenhos zootécnicos. Para que isso ocorra às aves usam mecanismos de proteção de defesa inespecífica e ou defesa específica (LAAN, 1999).

Segundo FAIRBROTHER et al. (2004) a defesa inespecífica corresponde a primeira barreira contra as agressões dos agentes infecciosos e é formada pela pele intacta e mucosa íntegra. A defesa específica precisa de contato prévio com o agente podendo ser através de infecção anterior ou de vacinação e, está estruturada sobre imunidade humoral e imunidade celular.

Células primordiais originam os linfócitos $T$ e $B$, estas células migram do saco vitelino para o timo e bolsa de Fabricius (órgãos linfóides), onde ocorrerá processo de multiplicação e maturação, diferenciando assim em linfócitos $T$, responsáveis pela imunidade celular e linfócitos $B$ responsáveis pela imunidade humoral (QURESHI, 2002).

FERKET (2003) relata que há uma inter-relação entre imunidade e nutrição. A nutrição é uma ferramenta usada para modular o sistema imune produzindo estado ideal de imunidade, que influencia diretamente em melhor desempenho zootécnico animal em decorrência da diminuição do estresse imunológico da ave, que desta maneira estará reduzindo a mobilidade de nutrientes para atividade que não estejam ligadas a produção para restabelecer a homeostasia. 
OLIVEIRA, M.D. et al. Aditivos alternativos na alimentação de aves. PUBVET, Londrina, V. 6, N. 27, Ed. 214, Art. 1425, 2012.

O estresse imunológico pode ser definido como uma exposição a um antígeno sofrida pela ave e, levando ao aumento da taxa metabólica, diminuição do apetite e redirecionamento dos nutrientes para atender as necessidades energéticas da resposta imune em vez do crescimento do músculo esquelético (RIBEIRO e RUDNIK, 2002; QURESHI, 2002).

Esses aditivos além de promoverem a modulação benéfica da microbiota intestinal possuem efeitos imunomoduladores que promovem a ativação do sistema imune. Estas bactérias benéficas ao animal obtêm a capacidade de produzir substâncias estimulantes (lipopolissacarideos e peptideoglicanas), sendo liberadas na luz intestinal (LODDI, 2003; NUNES, 2008) ou mesmo moléculas regulatórias da resposta imune para estabelecer a colonização da mucosa.

Existem alguns prebióticos específicos de acordo com COLLET (2000) que possuem a capacidade de alterar a função do sistema imune, por conseguirem fazer ligação a sítios de receptores dos macrófagos através de reconhecimento de açúcares nas glicoproteínas da superfície epitelial. Através desta ligação desencadearia uma reação em cascata que resultaria na ativação de macrófagos e liberação de citocinas, caracterizando a ativação da resposta imune adquirida.

MURAROLLI (2008) observou que o uso de prebiótico no peso relativo do baço, apresentou menor e não encontrou diferença entre os tratamentos para peso relativo do timo e bolsa de Fabricius. NUNES (2008) encontrou diferença quanto ao peso relativo do timo apresentando-se maior em dieta suplementada com prebiótico, o mesmo não o correu com a bolsa de Fabricius e o baço, que não deferiram em nenhum tratamento.

Para aves submetidas à dieta com prebiótico, notou-se menor peso relativo da bolsa de Fabricius, quando comparada ao tratamento com antibiótico (BITTENCOURT, 2006). 
OLIVEIRA, M.D. et al. Aditivos alternativos na alimentação de aves. PUBVET, Londrina, V. 6, N. 27, Ed. 214, Art. 1425, 2012.

\subsection{Aditivos}

O termo aditivo compreende substância, microrganismo ou produto formulado, adicionado intencionalmente aos alimentos com a finalidade de conservar, intensificar ou modificar suas propriedades indesejáveis, que não é utilizado normalmente como ingrediente e tenha ou não valor nutritivo e que melhore as características dos produtos destinados à alimentação animal ou dos produtos de origem animal e seu desempenho (MAPA, 2004).

Os aditivos são utilizados na alimentação com o objetivo de aumentar as taxas de crescimento e de sobrevivência, melhorar a saúde do trato gastrintestinal e a eficiência alimentar, poupar energia e reduzir as cargas patogênicas e a produção de dejetos, minimizando o impacto ambiental pela redução da transmissão de patógenos via alimentos (SILVA, 2004).

Conforme MENTEN (2002), esses microingredientes devem atuar de forma a melhorar o desempenho de maneira efetiva e econômica; são atuantes em pequenas quantidades; não proporcionam resistência cruzada com outros ingredientes de alimentação; e devem garantir a manutenção da microbiota gastrintestinal normal e benéfica; não são considerados tóxicos; não são mutagênicos ou carcinogênicos e não promovem efeitos deletérios ao ambiente.

\subsubsection{Classificação dos aditivos}

Os aditivos de acordo com a ação específica ou característica funcional são classificados em três classes: a primeira considerada a dos pronutrientes, aqueles microingredientes que podem favorecer a utilização dos nutrientes dietéticos pelos animais melhorando a sua eficiência de utilização e proporcionando melhor desempenho dos animais. Dentre eles incluem-se as substâncias acidificantes, adsorventes, aglutinantes, anticoccidianos, antifúngicos, antioxidantes, palatabilizantes, enzimas, pigmentantes, probióticos, prebióticos, simbióticos; a segunda inclui os coadjuvantes de 
OLIVEIRA, M.D. et al. Aditivos alternativos na alimentação de aves. PUBVET, Londrina, V. 6, N. 27, Ed. 214, Art. 1425, 2012.

elaboração considerados o microingrediente que pode ter efeito sobre as características físicas dos ingredientes ou da ração tais como cor, odor, consistência, conservação; e finalmente, a terceira que abrange os profiláticos que se tratam daqueles micronutrientes usados com o fim de previr a oxidação e destruição de vitaminas, a ocorrência de enfermidades ou intoxicações causadas por organismos patogênicos (MENTEN, 2002).

\subsubsection{Benefícios da utilização dos aditivos e justificativa para o seu uso}

De forma geral os sistemas intensivos de criação de frangos de corte impõem aos animais permanente desafio, uma vez que variações na composição e qualidade da ração, além do estresse imposto às aves, a idade dos animais e algumas doenças, causam alterações no pH e a presença de alguns metabólitos de microrganismos no intestino, culminam por alterar os índices morfométricos, interferindo na fisiologia e, portanto, na digestão e absorção de nutrientes (LOPES, 2008).

Nesse sentido todos os mecanismos de digestão e absorção de nutrientes são inerentes aos mecanismos fisiológicos do trato gastrintestinal do frango, sendo assim, a saúde intestinal tem relação estreita com os nutrientes presentes na dieta. Uma vez que esta é a via de entrada dos nutrientes para o melhor desenvolvimento da ave. E ainda, levando em consideração que a ração representa entre 70 a $80 \%$ do custo de produção, a integridade dos mecanismos fisiológicos de digestão e absorção dos nutrientes, isto é, a integridade das células epiteliais da mucosa, assegura o bom desempenho e produção (FURLAN et al., 2004).

Alguns nutrientes são essenciais para a homeostase intestinal, esses compostos têm a capacidade de estimular o desenvolvimento da mucosa intestinal e estão relacionados com a ingestão e digestão dos alimentos, com as propriedades químicas dos nutrientes presentes no lúmen intestinal. Tais substâncias são denominadas de agentes tróficos, os quais aceleram o processo de mitose que ocorre na região cripta-vilo, provocando assim o 
OLIVEIRA, M.D. et al. Aditivos alternativos na alimentação de aves. PUBVET, Londrina, V. 6, N. 27, Ed. 214, Art. 1425, 2012.

aumento no número de enterócitos (imaturos e maduros), e consequentemente alterando o tamanho dos vilos (BOARO, 2009).

Os benefícios da sua utilização referem-se à propriedade catalítica específica que esses ingredientes possuem, além de promoverem o equilíbrio da microbiota do trato digestório e reduzirem o pH facilitando a digestão e diminuindo a proliferação de microrganismos indesejáveis no estômago e intestino (MAPA, 2004). Esses alimentos ainda estimulam a imunidade dos animais e, em consequência disso melhoram as condições sanitárias dos lotes (SOUZA et al., 2006).

A pouca diversidade da microbiota intestinal de aves recém nascidas, além de ser considerada como um fator limitante para a digestão, também possibilita a colonização intestinal por patógenos entéricos. A ausência de contato com a microbiota natural, logo após o nascimento, pode afetar o desenvolvimento do trato gastrintestinal (TGI) e, por consequência, prejudicar o crescimento das aves. Assim, os efeitos negativos desse processo têm sido contornados com $O$ uso contínuo na ração de antibióticos em doses subterapêuticas (MAIORKA et al., 2001).

Entretanto, o uso dos antibióticos está sendo questionado devido à preocupação crescente referente à possibilidade desses ingredientes provocarem o crescimento de microrganismos resistentes, e essa resistência ser transferida aos microrganismos patogênicos que infectam o homem (BARRETO et al., 2007a).

Nesse aspecto, várias medidas têm sido estudadas para possibilitar o rápido desenvolvimento de bactérias no trato digestivo benéficas ao animal. Portanto, são necessárias alternativas como a utilização dos probióticos, prebióticos, simbióticos e aditivos fitogênicos para manutenção dos índices de produção alcançados (MAIORKA et al., 2001; BARRETO et al., 2007a; BARRETO et al., 2007b). 
OLIVEIRA, M.D. et al. Aditivos alternativos na alimentação de aves. PUBVET, Londrina, V. 6, N. 27, Ed. 214, Art. 1425, 2012.

\subsection{Probióticos}

Define-se como probiótico os produtos constituídos por microrganismos vivos que afetam beneficamente o animal, promovendo o equilíbrio da microbiota intestinal (FULLER, 1989). Esses microrganismos auxiliarão na recomposição da microbiota reduzindo a quantidade de microrganismos indesejáveis e estimulando o sistema imune das aves (BRASIL, 2004). Portanto, são considerados promotores de crescimento, o qual proporcionam aumento na produção de produtos de origem animal e melhor desempenho verificado pelo aumento do ganho de peso, melhor conversão alimentar entre outras variáveis (BERTECHINI e HOSSAIN, 1993; WOLKE et al., 1996; JIN et al., 1998; LORA et al., 2006; SILVA et al., 2006).

MARUTA (1993) observou aumento na quantidade de carne na carcaça, aumento da musculatura peitoral, diminuição da gordura abdominal, e diminuição do odor característico da carne de frango ao utilizar probiótico, mesmo contendo apenas uma cepa bacteriana. Em um trabalho realizado por JUNQUEIRA et al. (2006) obteve resultados semelhantes para o rendimento de carcaça, gordura abdominal e rendimento de partes (peito, asas, pernas e dorso).

Portanto de acordo com LORENÇON et al. (2007), para melhor eficiência os probióticos devem ser administrados já nos primeiros dias de vida, para que possam modular beneficamente a microbiota intestinal, através dos seus mecanismos de ações benéficos ao animal. Assim favorecendo melhores índices zootécnicos, com maior produtividade, um melhor estímulo do sistema imune, antes de serem contaminados por alguns patógenos (FULLER, 1989; ANDREATTI FILHO e SILVA, 2005).

\subsubsection{Microrganismos utilizados como probióticos e suas ações}

De acordo com LEEDLE (2000), as espécies de bactérias e leveduras normalmente utilizadas são: Lactobacillus acidophilus, L. brevis, L. bulgaricus, 
OLIVEIRA, M.D. et al. Aditivos alternativos na alimentação de aves. PUBVET, Londrina, V. 6, N. 27, Ed. 214, Art. 1425, 2012.

L. casei, L. cellobiosus, L. fermentum, L. helveticus, L. lactis, L. paracasei, L. plantarum, L. reuteri, L. rhamnosus, Bifidobacterium adolescentis, B. animalis, B. bifidum, B. infantis, B. Iongum, B. thrmophilum, Streptococcus thermophilus, S. diacetylactis, Enterococcus lactis, Pediococcus pentosaceus, Propionibacterium acidipropionici, Bacillus licheniformis, B. subtilis, B. toyoi, Saccharomyces cerevisiae, Aspegillus Níger, A. oryzae.

Segundo SILVA (2000), a utilização dos probióticos pode auxiliar na digestão e absorção de nutrientes, quando agem envolvendo a bioquímica digestiva, principalmente em relação à ação desses microrganismos sobre os sais biliares; pode ter ação inibitória no crescimento de bactérias patogênicas, com a produção de bacteriocinas que agem inibindo o crescimento de outras bactérias; podem produzir metabólitos que inibem bactérias gram negativas e positivas patogênicas; produzem vitaminas do complexo $B$; produzem lactato e acetato que reduzem $\mathrm{opH}$ do meio, exercendo efeito antibacteriano e proporcionando maior absorção de ácidos graxos de cadeia curta. Alguns gêneros de bactérias intestinais como Lactobacillus e Bifidobacterium estão diretamente relacionados com o aumento da resposta imune, produção de anticorpos, ativação de macrófagos, proliferação de células $T$ e produção de interferon (MENTEN, 2001); ativação do sistema imunológico contra células malignas; restauração da microbiota intestinal após antibioticoterapia.

2.4.2 Pré-requisitos para um microrganismo ser considerado probióticos e mecanismos de ação

O microrganismo para ser considerado probiótico deve sobreviver às condições adversas do trato gastrintestinal (TGI) como da ação da bile e dos sucos gástrico, pancreático e entérico, também esse aditivo deve constituir a microbiota normal do intestino do animal. É necessário que sobreviva e colonize rapidamente o intestino da ave e deve ser capaz de aderir ao epitélio intestinal do hospedeiro, ter ação antagonista aos microrganismos 
OLIVEIRA, M.D. et al. Aditivos alternativos na alimentação de aves. PUBVET, Londrina, V. 6, N. 27, Ed. 214, Art. 1425, 2012.

patogênicos, não ser tóxico ou patogênico e ser estável e viável na preparação comercial (GIBSON e ROBERFROID, 1995)

Várias ações benéficas na produção animal são atribuídas ao uso dos probióticos, que reflete diretamente em aumento da produtividade, entretanto, seu mecanismo de ação ainda não está inteiramente elucidado. Os principais mecanismos de ação dos probióticos compreendem em competição pelo sítio de adesão, atividade antimicrobiana, aumento da imunidade e efeito nutricional (MENTEN, 2002).

\subsubsection{Competição pelo sítio de adesão - Exclusão Competitiva (EC)}

O fornecimento de grandes quantidades de microrganismos probióticos promove a ocupação dos sítios de ligação (receptores) da mucosa entérica, ou seja, uma população de microrganismos torna-se incapaz de se estabelecer no intestino, devido à presença de outra população diminuindo a área de interação das bactérias patogênicas, atuando como barreira física contra esses microrganismos, que são eliminados por não se ligarem aos receptores celulares, são excluídos pela competição por ocupação física (TOLEDO, 2009). Assim as bactérias patogênicas seriam excluídas por competição de espaço (FURLAN et al., 2004).

Conforme CUARÓN (2000) a maioria dos probióticos pode interagir com a membrana intestinal, formando uma parede de defesa contra os patógenos invasores, ou seja, formam uma "película biológica", que evita a aderência dos microrganismos indesejáveis. No caso das leveduras do gênero Saccharomyces, estas aderem aos microrganismos patogênicos em sua parede celular, com a formação de um "complexo levedura-bacteria", que aumenta a susceptibilidade aos mecanismos de defesa da ave. 
OLIVEIRA, M.D. et al. Aditivos alternativos na alimentação de aves. PUBVET, Londrina, V. 6, N. 27, Ed. 214, Art. 1425, 2012.

\subsubsection{Atividade antimicrobiana}

Os microrganismos probióticos podem atuar através da produção de ácido lático e acético que reduzem $\mathrm{o} \mathrm{pH}$ do trato gastrintestinal (TGI), impedindo assim o crescimento de patógenos, bem como pela produção de substâncias antimicrobianas como bacteriocinas e peróxido de hidrogênio. Muitas espécies de Lactobacillus e Bifidobacterium produzem substâncias consideradas antibióticos naturais de grande espectro de atividade (GIBSON, 1999).

As bacteriocinas são substâncias protéicas e antibióticas de ação local, que irão inibir o crescimento de patógenos intestinais (LODDI, 2002). A produção de ácidos por bactérias láticas pode inibir o crescimento de patógenos por dois mecanismos: além da diminuição do pH ocorre efeito direto dos ácidos sobre as bactérias (PELICANO et al., 2002). Algumas bactérias secretam enzimas, como a p-glucoronidase e hidrolases de sais biliares, que liberam compostos, como ácidos biliares, com ação inibitória sobre outras bactérias (SILVA, 2000).

\subsubsection{Aumento da imunidade}

As bactérias produtoras de ácido láctico aumentam a atividade de macrófagos e linfócitos, há também a produção de vitaminas e o aumento da digestão dos carboidratos, impedindo assim que estes sirvam como substrato para o crescimento de patógenos. O papel exato através do qual os probióticos e a parede celular de leveduras estimulam o sistema imunológico não são adequadamente conhecidos (CUARÓN, 2000).

Lactobacillus podem ser importantes no desenvolvimento de imunocompetência em animais jovens, particularmente quando é necessária proteção contra antígenos que causam reações inflamatórias no intestino. Um aspecto que parece ser contraditório e necessita ser esclarecido é que normalmente se considera que a ativação excessiva do sistema imune resulta 
OLIVEIRA, M.D. et al. Aditivos alternativos na alimentação de aves. PUBVET, Londrina, V. 6, N. 27, Ed. 214, Art. 1425, 2012.

em depressão no crescimento, sendo que os antibióticos promotores do crescimento atuariam reduzindo essa ativação. No caso do fornecimento de probióticos, a interpretação é que o sistema imune das aves já estaria preparado para reagir aos antígenos, podendo neutralizá-los sem que haja uma ativação excessiva (ANDREATTI FILHO e SAMPAIO, 1999; LEEDLE, 2000; PELICANO et al., 2002).

\subsubsection{Efeito nutricional}

Nas aves devido o seu trânsito da ingesta ser rápido, a atividade da microbiota promovida por probióticos pode ser suficiente para aumentar a produtividade. Uma serie de efeitos que pode levar ao aumento da digestão ou absorção de nutrientes, como a simples redução do pH intestinal por bactérias láticas, que proporciona maior absorção de ácidos de cadeia curta (LEEDLE, 2000).

De acordo com JIN et al. (1997), os probióticos promovem alguma digestão de celulose em aves e que os Lactobacillus secretam amilase, protease e lipase. Em um trabalho realizado por TOURNUT (1998), apresentou dados no qual foi comparado o uso de um probiótico na dieta de frangos e outra com antibiótico, levando à melhor resultado no aumento nos valores de energia metabolizável da dieta e da digestibilidade da gordura no tratamento com probiótico. BERTECHINI e HOSSAIN (1993) encontraram resultado na melhora do desempenho de frangos de corte suplementados com probióticos. JUNQUEIRA et al. (2006), também obteve bons resultados no ganho de peso e conversão alimentar em frangos avaliados de 1 a 21 dias de idade, alimentados com rações contendo o probiótico e o prebiótico.

\subsubsection{Modo de administração dos probióticos}

A via de administração dos probióticos pode, também, determinar melhor ou pior capacidade de colonização intestinal pelas bactérias presentes no 
OLIVEIRA, M.D. et al. Aditivos alternativos na alimentação de aves. PUBVET, Londrina, V. 6, N. 27, Ed. 214, Art. 1425, 2012.

produto utilizado. Sabe-se que a maioria dos microrganismos são sensíveis a alta temperatura e geralmente podem ser destruídos pela peletização das rações, a utilização de cepas termoestáveis pode ser uma alternativa à possibilidade do processo de peletização sem comprometer a eficiência (EYNG et al., 2006). Estudos sobre qual a melhor forma de aplicação dos probióticos não está elucidado, mas independente da via devem ser administrados às aves o mais precocemente possível. O modo de administração dos probióticos pode ser o mais variado possível, podendo ser adicionado na ração, na água de beber, pulverização sobre as aves, inoculação em ovos embrionados, através da cama usada em cápsulas gelatinosas e via intra-esofagiana (SILVA, 2000; ANDREATTI FILHO e SILVA, 2005).

EYNG et al. (2006), em um trabalho cujo objetivo foi de avaliar o efeito da utilização de probióticos em rações fareladas e peletizadas sobre o desempenho de pintos de corte de 1 a 21 dias de idade, observou-se 0 seguinte resultado que não houve diferença significativa nas forma física da ração nas variáveis de desempenho avaliadas: ganho de peso, peso final, consumo de ração, conversão alimentar e mortalidade. Outros autores obtiveram resultados semelhantes (HENRIQUE et al., 1998; ARAÚJO et al., 2000; CORRÊA et al., 2000; LORENÇON, 2006a; LORENÇON, 2006b).

\subsection{Prebióticos}

Os prebióticos são definidos como ingredientes alimentares que não sofrem ação das enzimas digestivas do animal, são constituídos por carboidratos que não são digeridos na porção proximal do trato gastrintestinal dos monogástricos, mas estimulam seletivamente o crescimento e ou a atividade de bactérias benéficas no intestino e reduzem a colonização intestinal por bactérias enteropatogênicas (GIBSON e ROBERFROID, 1995).

Indiretamente, os prebióticos além de atuarem no sistema imune também atuam no sistema enzimático, por promover o crescimento das populações de bactérias benéficas (Lactobacillus e Bifidobacterium). Estas tem 
OLIVEIRA, M.D. et al. Aditivos alternativos na alimentação de aves. PUBVET, Londrina, V. 6, N. 27, Ed. 214, Art. 1425, 2012.

a capacidade de produzir substâncias com propriedades imunoestimulatórias e interagir com o sistema imune em vários níveis, incluindo a modulação da resposta, a produção de citocinas, a proliferação de células mononucleares, a estimulação da fagocitose macrofágica, a eliminação e a indução de síntese de grandes quantidades de imunoglobulinas, em especial, as IgA (SILVA e NORNBERG, 2003; FLEMMING, 2005).

\subsubsection{Ingredientes utilizados como prebióticos}

Os prebióticos mais estudados como aditivos na alimentação animal são os oligossacarídeos, especialmente os mananoligossacarídeos (MOS), os frutoligossacarídeos (FOS) e os glucoligossacarídeos (GOS) (ROSTAGNO et al., 2003). Segundo FERNANDES et al. (2003), os mananoligossacarídeos são carboidratos complexos contendo D-manose, derivados da parede celular de leveduras (Saccharomyces cerevisiae) sendo principalmente composto por carboidratos e proteínas. Segundo MENTEN (2001), os mananoligossacarídeos parecem ter características específicas que permitem impedir a colonização intestinal por patógenos. Muitos patógenos utilizam fimbrias para adesão à mucosa intestinal, essa adesão ocorre em receptores constituídos de manose que é necessária para que ocorra a colonização. Os MOS adicionados à dieta podem aderir às fimbrias bacterianas, bloqueando a adesão das bactérias à superfície intestinal.

Possuem como funções principais a melhoria e a proteção da mucosa, reduzindo as lesões intestinais e propiciando maior altura dos vilos e profundidade de cripta, (LUQUETTI et al., 2005; PELICANO et al., 2005), além de aumentar a digestibilidade de nutrientes e o teor da energia metabolizável das rações, pois propicia o desenvolvimento da microbiota intestinal (ALBINO et al., 2006).

Os MOS também possuem a capacidade de serem utilizados como adsorventes de aflatoxinas, pois diminuem os problemas causados pelas 
OLIVEIRA, M.D. et al. Aditivos alternativos na alimentação de aves. PUBVET, Londrina, V. 6, N. 27, Ed. 214, Art. 1425, 2012.

micotoxinas, normalmente presentes no milho de baixa qualidade (STRINGHINI et al., 2000).

Os frutoligossacarídeos (FOS) são polímeros ricos em frutose, podendo ser naturais derivados de sementes e raízes de alguns vegetais como a chicória, cebola, alho, alcachofra, aspargo, cevada, centeio, grãos de soja, grão-de-bico e tremoço, ou sintéticos, resultantes da polimerização de frutose Os FOS pode resultar em uma melhora do desempenho animal (ROSTAGNO et al., 2003).

Os glucoligossacarídeos (GOS) de acordo com MENTEN (2001) são obtidos a partir da parede celular de leveduras e contêm glucose e manose, como os dois principais açúcares.

\subsubsection{Ações benéficas atribuídas ao uso de prebióticos}

As substâncias prebióticas agem alimentando e estimulando o crescimento de diversas bactérias intestinais benéficas, cujos metabólitos atuam, também, reduzindo o $\mathrm{pH}$ através do aumento da quantidade de ácidos orgânicos presentes nos cecos. Por outro lado, bloqueiam os sítios de aderência (principalmente a D-Manose), imobilizando e reduzindo a capacidade de fixação de algumas bactérias patogênicas na mucosa intestinal; promovem redução dos lipídios sanguíneos; melhor absorção do cálcio da dieta; auxíliam em várias condições inflamatórias do TGI melhoram a função de barreira e do tecido linfóide associado ao intestino e estimula a produção de IgA (GOMES, 2009).

2.5.3 Pré-requisitos para um ingrediente ser considerado prebiótico e mecanismos de ação

O componente do alimento para ser considerado prebiótico, não deve ser hidrolisado, digerido ou absorvido nos segmentos iniciais do trato digestivo; 
OLIVEIRA, M.D. et al. Aditivos alternativos na alimentação de aves. PUBVET, Londrina, V. 6, N. 27, Ed. 214, Art. 1425, 2012.

deve servir de substrato para as bactérias intestinais potencialmente benéficas, que serão estimuladas a crescer ou tornarem-se metabolicamente ativas; deve haver a disposição de alterar a microbiota intestinal de forma benéfica ao hospedeiro, favorecendo uma composição mais saudável e induzir efeitos benéficos na luz intestinal, ou sistêmicos ao animal (GIBSON e ROBERFROID, 1995; LODDI, 2001; DIONÍZIO et al., 2002).

Para que ocorra o mecanismo de ação dos prebióticos as bactérias devem colonizar o trato intestinal e criar uma condição patológica e para que isso aconteça precisam inicialmente aderir-se à superfície epitelial. Esta adesão ocorre através de glicoproteínas (lectinas ou fímbrias) que reconhecem determinados açúcares da superfície do epitélio intestinal (NUNES, 2008). Deste modo, as bactérias se ligam a um oligossacarídeo dietético, e não ao açúcar da superfície da mucosa intestinal, o que faz com estas sejam eliminadas passando com a digesta, pelo trato intestinal sem causar problemas digestivos para os animais. Desta forma, os mananoligossacarídeos são capazes de bloquear a aderência dos patógenos e evitar a colonização (IJI e TIVEY, 1998).

COLLETT (2000) relata que a alteração da microbiota intestinal originada pelo uso de prebióticos pode incidir de duas maneiras: através do fornecimento de nutrientes para as bactérias benéficas aumentando sua população; ou pelo reconhecimento por parte das bactérias patogênicas, de sítios de ligações nos oligossacarídeos como sendo da mucosa intestinal, diminuindo assim a colonização intestinal indesejável, resultando em menor incidência de infecções e melhor integridade da mucosa intestinal, tornando esta apta a exercer suas funções.

\subsection{Simbióticos}

De acordo com MENTEN (2002), o termo simbiótico significa o fornecimento conjunto de microrganismos probióticos e de substâncias 
OLIVEIRA, M.D. et al. Aditivos alternativos na alimentação de aves. PUBVET, Londrina, V. 6, N. 27, Ed. 214, Art. 1425, 2012.

prebióticas específicas que estimulem seu desenvolvimento e atividade, potencializando o efeito de ambos os produtos.

Esta associação é uma alternativa bastante interessante no sentido de melhorar a sanidade do intestino delgado e cecos das aves, através dos mecanismos fisiológicos e microbiológicos. A ação simbiótica estabiliza o meio intestinal e aumenta o número de bactérias benéficas produtoras de ácido láctico, favorecendo a situação de eubiose (FULLER, 1989; FURLAN et al., 2004).

A microbiota é beneficiada pela ação dos prebióticos que têm a capacidade de se ligarem às fimbrias de bactérias patogênicas, conduzindo-as juntamente ao bolo fecal, estimulando o desenvolvimento e acelerando o metabolismo de limitado número de microrganismos não patogênicos. A essa ação soma-se a dos probióticos, facilitando a nutrição de enterócitos que recobrem o trato digestório e proporcionando equilíbrio e saúde intestinal as aves (GIBSON; ROBERFROID, 1995).

Conforme SILVA (2000) a interação dos microrganismos probióticos com os prebióticos possui a capacidade de modulação de respostas imunes sistêmicas, aumentando o número e atividade de células fagocitárias do hospedeiro. Essa ação é de suma importância nas aves, pois o trato intestinal é o órgão de maior responsabilidade no desenvolvimento de imunidade geral e inespecífica.

As aves não possuem linfonodos, então alguns folículos linfóides estão espalhados ao longo do trato intestinal e são representados pelas placas de Peyer, tonsilas cecais e pela bolsa de Fabrícius, ou bolsa cloacal. Esses tecidos linfóides são sensíveis aos antígenos presentes no trato gastrintestinal como os probióticos e o MOS que agem estimulando as células B precursoras de IgA e células $\mathrm{T}$ colaboradoras das placas de Peyer para o desenvolvimento da imunidade geral e inespecífica. Através do estímulo imunológico da mucosa ocorre a produção de anticorpos tipo IgA, que diminuem o número de bactérias patogênicas na luz intestinal e produção de interferon, entre outros, determinando aumento da imunidade das mucosas (SILVA, 2000). 
OLIVEIRA, M.D. et al. Aditivos alternativos na alimentação de aves. PUBVET, Londrina, V. 6, N. 27, Ed. 214, Art. 1425, 2012.

BALOG et al. (2007) adicionaram simbiótico na alimentação de frangos de corte e verificaram que houve melhor desempenho, sem alterar a biometria gastrintestinal e a morfometria do epitélio gastrintestinal.

De acordo com SCHWARZ (2002), é possível substituir os antibióticos pelos probióticos, prebióticos e simbióticos sem causar perdas no desempenho das aves.

\subsection{Aditivos Fitogênicos, Extratos Vegetais e óleos Essenciais}

Com a preocupação crescente da população em relação à qualidade dos alimentos e as restrições impostas pela União Européia a respeito do uso de antimicrobianos na alimentação animal aumenta-se a demanda por pesquisa com produtos naturais (BARRETO, 2007).

Os efeitos benéficos das plantas estão associados com a constituição de seus princípios ativos e compostos secundários. Considerando a vasta variedade de plantas existentes, constituídas por inúmeras substâncias, o grande desafio na utilização de extratos vegetais, como aditivo alimentar consiste na identificação e quantificação dos efeitos exercidos pelos diferentes componentes presentes nos óleos essenciais sobre o organismo animal. Recentemente espécies vegetais como alho, manjerona, orégano, hortelã, alecrim, tomilho, zimpro, pimenta vermelha e cebola despertam interesse dos pesquisadores da nutrição animal, pois possuem princípios ativos que poderiam trazer benefícios aos animais. Portanto esses aditivos fitogênicos, extratos herbais e extratos vegetais, fazem parte de uma classe de produtos que poderão substituir os agentes antimicrobianos, devido aos efeitos benéficos associados aos seus princípios ativos e compostos secundários (KAMEL, 2000).

Os extratos vegetais possuem a capacidade de aprimorar o desempenho dos animais pelos seguintes mecanismos: aumentam a palatabilidade da ração; estimulam a secreção de enzimas endógenas e da função digestiva; 
OLIVEIRA, M.D. et al. Aditivos alternativos na alimentação de aves. PUBVET, Londrina, V. 6, N. 27, Ed. 214, Art. 1425, 2012.

possuem efeito trófico da mucosa, modulam a microbiota intestinal e auxiliam na redução de infecções subclínicas (LAUGHOUT, 2005).

Segundo KOHLERT et al. (2000), os princípios ativos dos extratos vegetais são absorvidos no intestino pelos enterócitos e metabolizados rapidamente no organismo animal.

Os óleos essenciais constituem-se complexas misturas de substâncias voláteis, geralmente lipofílicas, cujos componentes incluem hidrocarbonetos terpênicos, álcoois simples, aldeídos, cetonas, fenóis, ésteres, ácidos orgânicos fixos, etc, em diferentes concentrações, nos quais, um composto farmacologicamente ativo é majoritário (SIMÕES e SPITZER, 1999). No orégano, o carvacrol está presente em concentrações que varia 3 a $17 \%$; no tomilho encontra-se $40 \%$ de timol e na canela tem-se $75 \%$ de cinamaldeído (FARMACOPEA ITALIANA, 1998).

Estes compostos são produzidos como mecanismo de defesa da planta contra fatores externos como estresse fisiológico, fatores ambientais e proteção contra predadores e patógenos (HUYGHEBAERT, 2003).

A substância que constitui o princípio ativo de um óleo essencial pode ser encontrada em diversas plantas, com diferentes concentrações. O timol, por exemplo, pode ser encontrado no tomilho e no orégano, porém com diferentes concentrações $40 \%$ e $10 \%$ respectivamente. Apesar da presença do timol nas duas ervas ele é considerado princípio ativo do tomilho, pois o princípio ativo do orégano é o carvacrol (KAMEL, 2000).

De forma geral, os óleos essências modificam a microbiota intestinal e reduzem a carga microbiana ao impedir a proliferação de bactérias, fungos, protozoários e vírus, melhoram a renovação do revestimento intestinal e evita ataque de parasitas, permitindo o desenvolvimento de células mais saudáveis (BRUERTON, 2002).

No processo digestivo, a presença de enzimas é fundamental para a digestão de nutrientes. Para que os extratos das plantas possam estimular a produção de saliva e dos sucos gástrico e pancreático, beneficiando a secreção enzimática e melhorando a digestibilidade dos nutrientes (MELLOR, 2000). 
OLIVEIRA, M.D. et al. Aditivos alternativos na alimentação de aves. PUBVET, Londrina, V. 6, N. 27, Ed. 214, Art. 1425, 2012.

A capsaicina componente ativo da pimenta vermelha e o cinamaldeído presente na canela têm-se mostrado eficientes em estimular as enzimas pancreáticas e intestinais em animais monogástricos. Promovendo a redução na viscosidade intestinal e melhorando o processo de digestão dos alimentos (WANG e BOURNE, 1998).

Outro exemplo desses aditivos fitogênicos é o alho, de nome científico Allium sativum, cujos princípios ativos e composição são (alicina, alinasa, inulina, nicotinamida, galantamina, garlicina, FOS, ácidos fosfórico, sulfúrico, vitaminas $A, B$ e $C$, proteínas e sais minerais) tem sido testado em animais, para o controle de parasitas e como um auxiliar no crescimento. Possui efeito antidiarréico, antiinflamatório, anticéptico, antifúngico, antiviral, anticarcinogênico, antioxidante, facilita a desintoxicação hepática e renal, é imunoestimulante e exerce efeito trófico na mucosa intestinal (SANTOS, 2010).

A propriedade de imunoestimulação do alho está relacionada com os altos teores de zinco e selênio, ambos considerados metais antioxidantes, e também com a presença de substâncias que promovem a proliferação de células $T$ e de citocinas produzidas por macrófagos, estimulando a imunidade humoral e a celular. Além disso, o alho possui propriedades hipoglicêmicas, reduzindo a glicose sanguínea por estimular a secreção de insulina pelas células endócrinas do pâncreas (QUINTAES, 2001).

FREITAS et al. (2001) com o objetivo de avaliar a utilização do alho na alimentação de frangos de corte, como promotor de crescimento, apesar da ausência de desafio ambiental neste experimento, notaram que o alho não exerceu efeito positivo no crescimento, ou os níveis utilizados não foram suficientes para originar efeito no crescimento das aves.

Outro resultado semelhante foi encontrado por CARRIJO et al. (2005), no qual a inclusão do alho em pó beneficiou a conversão alimentar, porém não substituiu com eficácia o antibiótico usado como promotor de crescimento. No entanto, SHI et al. (1999), ao fornecerem $0,2,1,0$ ou 2,0 \% de alho em dietas de frango de corte, verificaram redução da mortalidade, maiores peso corporal 
OLIVEIRA, M.D. et al. Aditivos alternativos na alimentação de aves. PUBVET, Londrina, V. 6, N. 27, Ed. 214, Art. 1425, 2012.

e consumo de ração e melhores índices econômicos com o nível de 1,0\% de alho na dieta.

\section{CONSIDERAÇÕES FINAIS}

A utilização de aditivos alternativos como promotores de crescimento na dieta de aves é viável em substituição aos antibióticos, pois resultados significativamente positivos foram obtidos em relação ao desempenho.

\section{REFERENCIAS BIBLIOGRÁFICAS}

ALBINO, L. F.T; BUNZEN, S; ROSTADNO, H. S. Ingredientes promotores de desenvolvimento para frangos de corte. In: SEMINÁRIO DE AVES E SUÍNOS, 7. 2007, Belo Horizonte.

Anais...Belo Horizonte: AveSui, 2007. P. 73-90.

ALBINO, L.F.T.; FERES, F.A.; DIONIZIO, M.A.Uso de prebiótico à base de mananoligossacarideo em rações para frangos de corte. Revista Brasileira de Zootecnia, v.35, n.3, p.742-749, 2006.

ANDREATTI FILHO, R. L.; SAMPAIO, H. M. Probióticos e prebióticos. Rev. Educ. Continuada do CRMV- SP, 2:59-71. 1999.

ANDREATTI FILHO, R.L; SILVA, E.N. Probióticos e correlatos na produção avícola. In: PALERMO NETO,T. SPINOSA, H.S.; GORNIAK, S.L. Farmacologia aplicada à avicultura. São Paulo. Roca, 2005. Cap. 15, p. 225-248.

ARAúJO, J. A; SILVA, J. H. V. AMÂNCIO, A. L. L; LIMA, M. R. LIMA, C. B. Uso de aditivos na alimentação de aves. Acta Veterinaria Brasilica, v. 1, n. 3, p. 69-77, 2007.

ARAÚJO, L.F.; JUNQUEIRA, O.M.; ARAÚJO, C.S. Reunião anual da Sociedade Brasileira de Zootecnia 2000, 7:254.

BALOG, A; MENDES, A. A; TAKAHASHI, S. E; SANFELICE, C; KOMYAMA, C. M; ALMEIDA, I. C. L; GARCIA, R. G. Efeito do uso de simbiótico e do sistema de criação sobre o desempenho e morfometria do epitélio intestinal de frangos de corte tipo colonial. . Revista Brasileira de Ciência Avícola. Campinas, Suplemento 9, p.140, 2007.

BARRETO, M. S. R.; MENTEN, J. F. M; RACANICCI, A. M. C; PEREIRA, P. W. Z; RIZZO, P. V. Extratos vegetais como promotores do crescimento no desempenho de frangos de corte.

Revista Brasileira de Ciência Avícola. Campinas, Suplemento 9, p.32, 2007a.

BARRETO, M. S. R.; MENTEN, J. F. M; RACANICCI, A. M. C; PEREIRA, P. W. Z; RIZZO, P. V. Energia metabolizável de rações suplementadas com extratos vegetais. Revista Brasileira de Ciência Avícola. Campinas, Suplemento 9, p.33, 2007b. 
BERTECHINI, A.G.; HOSSAIN, S.M. Utilização de um tipo de probiótico como promotor de crescimento em rações de frangos de corte. In: CONFERÊNCIA DE CIÊNCIA E TECNOLOGIA AVÍCOLAS, 1993, Santos. Anais... Santos: APINCO, 1993. p.1.

BITTENCOURT, L. C. Efeitos da utilização de probióticos sobre parâmetros da resposta imune, hematológicos e de desempenho de frangos de corte. 2006. 98f. Dissertação ( Mestrado em Medicina Veterinária). Faculdade de Medicina Veterinária e Zootecnia, Universidade de São Paulo, SP, 2006.

BOARO, M. Morfofisiologia do trato intestinal. In: CONFERENCIA FACTA DE CIENCIA E TECNOLOGIA AVICOLAS, 27, Porto Alegre, RS. Anais... Porto Alegre: FACTA, 2009.

BORGES, F. M. O; SALGARELO, R. M; GURIAN, T. M. Alimento Funcional. Disponível em: http://www.portaleducacao.com.br/veterinaria/artigos Acessado: 30 de Setembro de 2011.

BUTOLO, J. E. Uso de aditivos na alimentação das aves: frangos de corte. In: SIMPÓSIO SOBRE AS IMPLICAÇÕES SÓCIO-ECONÔMICAS DO USO DE ADITIVOS NA NUTRIÇÃO ANIMAL, 1999, Piracicaba. Anais...Piracicaba: CBNA, 1999.

BRASIL, Ministério da Agricultura. Instrução Normativa n.13, de 30 de Novembro de 2004. Regulamento técnico sobre aditivos para produtos destinados à alimentação animal, segundo as boas práticas de fabricação, contendo os procedimentos sobre avaliação de segurança de uso, registro e comercialização, constante dos anexos desta instrução normativa. Brasília, 2004.

BRITO, A. B.; LEANDRO, N. S. M., STRINGHINI, J. H. et al. Desempenho e digestibilidade de nutrientes para frangos alimentados com rações contendo promotor de crescimento (Olaquindox) e probiótico (Bacillus) Acta Scientiarum, v.27,n.3,p.327-332, 2005.

BRUERTON, K. Antibiotic growth promoters - are there alternatives? In: POULTRY INFORMATION EXCHANCE ORGANISING COMMITTEE, 2002, Caboolture. Anais... Caboolture: PIX, p. 171-176, 2002.

CANALLI, L.S.; FLEMMING, J.S.; MIRA, R.T.; BRASILE, L.F. Alteração da microbiota intestinal de frangos de corte pela utilização de probiótico na alimentação. Revista do Setor de Ciências Agrária, Curitiba, v.15, n.1, p. 125-132, 1996.

CARRIJO, A.S.; MADEIRA, L.A.; SARTORI, J.R.; PEZZATO, A.C.; GONÇALVES, J. C.; CRUZ, V.C.; KUIBIDA, K.V.; PINHEIRO, D.F. Alho em pó na alimentação alternativa de frangos de corte. Pesquisa Agropecuária Brasileira, v.40, n.7, Brasília, jul., 2005.

COLLET, J.E. Uso de aditivos e produtividade. In. RONDA LATINO AMERICANA DA ALLTECH, 10., 2000, Campinas, São Paulo. Anais...Campinas: 2000. P. 20-30.

CORNELI, J. Avaliação de promotores de crescimento alternativos em substituição aos convencionais sobre o desempenho, características de carcaça e morfometria intestinal em frangos de corte. Santa Maria - RS, 2004.

CORRÊA, G. S. S; GOMES, A. V. C. CORRÊA, A. B. Arquivo Brasileiro de Medicina Veterinaria e Zootecnia, 2000; 55 (4).

CUARÓN, J.A.I. LA influéncia de la levadura en la dieta, respuesta microbiológica antagonista. In: Simpósio Sobre Aditivos Alternativos na Nutrição Animal, 2000, Campinas. Anais...

Campinas: Colégio Brasileiro de Nutrição Animal, 2000. p.71-79. 
DIONIZIO, M. A, BERTECHINI, G. A., KANJI KATO, R. TEIXEIRA, A. S. Prebióticos como promotores de crescimento para frangos de corte - desempenho e rendimento de carcaça, CIÊNCIA E AGROTECNOLOGIA, Lavras. Edição Especial, p. 1580-1587, 2002.

EYNG, C; NUNES, R.V; POZZA, P.C.; POZZA, P.C; POZZA, M.S.S; LORENÇON, L, SILVA, WTM. Avaliação de probióticos para pintos de corte de 1 a 21 dias de idade em rações fareladas e peletizadas. Revista Brasileira de Ciência Avícola. Campinas, Suplemento 8, p.51, 2006.

FAIRBROTHER, A. SMITS, J. GRASMAN,K. A. Avian immunotoxicology. Journal of Toxicology and Envirommental Health. v. 7, p. 105-137, 2004.

FERNANDES, P.C.C.; MALAGUIDO, A.; SILVA, T.D.; JENSEN, B.B. Manejo nutricional visando substituir a utilização de antimicrobianos em alimentos para aves. In:SIMPÓSIO SOBRE MANEJO E NUTRIÇÃO DE AVES E SUÍNOS, 2003, Campinas, SP. Anais...Campinas:CBNA, 2003.p135-166.

FERKET, P. R. Manutenção da saúde intestinal em mundo sem antibióticos. In: $13^{\circ}$ RONDA LATINO AMERICANA DA ALLTECH, 13, 2003, Campinas. Anais... Campinas: Alltech, 2003, p. 26- 39.

FINCH, J. M. \& TURNNER, R. J. Effects of selenium and vitamin E on the immune responses of domestics animals. Research in Veterinary Science, Oxford, UK , v.60, 0. 97-106,1996.

FULLER, R. Probiotics in man and animals. A review. J. Appl. Bacteriol., v.66, p. 365-378, 1989.

FURLAN, R. L.; MACARI, M.; LUQUETTI, B. C. Como avaliar os efeitos do uso de prebióticos, probióticos e flora de Exclusão Competitiva. In: $5^{\circ}$ Simpósio Técnico de Incubação, Matrizes de Corte e Nutrição. Anais... Balneário Camboriú, p. 6-28, 2004.

FUKAYANA, E. H; BERTECHINI, A. G; GERALDO, A; KATO, R. K; MURGAS, L. D. S. Extrato de Orégano como Aditivo em Rações para Frangos de Corte. Revista Brasileira de Zootecnia, v.34, n.6, p.2316-2326, 2005.

FLEMMING.J.S. Utilização de leveduras, probióticos e mananoligossacarideos (MOS) na alimentação de frangos de corte. 2005. 109 f. Teses (Doutorado em Tecnologia de Alimentos)- Universidade Federal do Paraná, 2005.

FREITAS, R.; FONSECA, J.B.; SOARES, R.T.R.N.; ROSTAGNO, H.S.; SOARES, P.R. Utilização do Alho (Allium sativum L.) como Promotor de Crescimento de Frangos de Corte. Rev. Bras. Zootec., Viçosa, v. 30, n. 3, mai/jun, 2001.

GIBSON G. R., ROBERFROID M.B. Dietary modulation of the human colonic microbiota: Introducing the concepto f prebiotics. Journal of Nutrition, v. 125: p. 1401- 1412, 1995.

GIBSON, G.R. Dietary modulation of the human gut microflora using the prebiotics oligofructose and inulin. Journal of Nutrition, v.129, n. 7, p.1438-1441, 1999.

GOMES, M.O.S. (2009). Efeito da adição de parede celular de levedura sobre a digestibilidade, microbiota fecal e parâmetros hematológicos e imunológicos de cães. Dissertação de Mestrado em Jaboticabal, São Paulo: Faculdade de Ciências Agrárias e Veterinárias da Universidade Estadual Paulista.

HENRIQUE, L. Z.; HO, Y. W. Abdullah N. Poutry Science 1998; 77:1259-1265. 
HUYGHEBAERT, G. Replacement of antibiotics in poultry, In: EASTERN NUTRITION CONFERENCE, v. 80, Quebec City. Anais... Quebec City: UON, p. 1-23, 2003.

IJI, P.A.; TIVEY, D.R. Natural and synthetic oligosaccharides in broiler chicken diets. World's Poultry Sci., 77:1259-1265. 1998.

JIN, L. Z.; HO, Y.W.; ABDULLAH, N. Growth performance, intestinal microbial populacions, and serum cholesterol of broilers fed diets containing Lactobacillus cultures. Poult. Sci., v.77, p.1259-1265, 1998.

JIN, L. Z; HO, Y.W.; ABDULLAH, N; JALALUDIN, S. Probiotic in powtry: modes of action. Wold's Poultry Science Journal, v. 53, p. 351-368, 1997.

JUNQUEIRA, O.M. TANAKA, A.H. DALANEZI, J.A. GARCIA, E. A. DUARTE, K.F.DALANEZI, L.M. Antibiótico, probiótico, prebiótico e simbiótico sobre desempenho de frangos de corte de 21 dias de idade. Revista Brasileira de Ciência Avícola,. Campinas, Suplemento 8. p 60, 2006.

KAMEL, C. A novel look at a classic approach extracts. Feed Mix - The International Journal on Feed, Nutrition and Technology, Doetinchem, v.18, n.6, p. 19-24, 2000.

KOHLERT, C., VAN RENSEN, I., MARZ, R., et. al. Biovailability and pharmokinetics of natural volatile terpenes in animal and humans. Planta Médica, Stuttgart, v.66, p. 495-505, 2000.

KUZMUK, N.K.; SWANSON, K. S.; TAPPENDEN, K. A.; SCHOOK, L. B.; FAHEY JÚNIOR, G.C. Diet and age affect intestinal morphology and large bowel fermentative end product concentration in senior and young adult dogs. Journal of Nutrition, v. 135, p. 1940-1945, 2005.

LAAN, C. W. Fatores que afetam a respostas imunitária. In: Congresso de produção e Consumo de ovos. 1999, São Paulo: Anais... SP: Associação Brasileira de Avicultura, 1999, p. 43-52.

LUNA, L. G. Manual of histologic staining methods of the armed forces institute of pathology. 3 ed. New York: McGraw-hill, 258p.,1968.

LANGHOUT, P. Alternativas ao uso de quimioterápicos na dieta de aves: a visão da indústria e recentes avanços. In: CONFERÊNCIA APINCO DE CIÊNCIA E TECNOLOGIA AVÍCOLAS, Anais: Facta, p.21-33, 2005.

LEEDLE, J. Probiotics and DFMS- mode of action in the gastrointesninal tract. In: Simpósio sobre aditivos alternatives na nutrição animal. Anais. Campinas: CBNA, 2000. p. 25-40.

LODDI, M. M. Probióticos e prebióticos na nutrição de aves. Revista CFMV. 04/11/2002. Disponível em: www.cfmv.org.br/menu_revista/revistas/rev23/

tecnico5.btm//probio. Acessado em 30/09/2011.

LODDI, M. M. Probioticos, prebióticos e acidificantes orgânicos em dietas para frangos de corte, 2003. 52 f. Tese ( Doutorado em Zootecnia). Faculdade de Ciências Agrárias e Veterinária, Universidade Estadual Paulista "Julio de Mesquita Filho", Jaboticabal, 2003.

LORA, G. A. Uso de probióticos em rações de frangos de corte. Viçosa, UFV, 2006. Dissertação (Mestrado em Zootecnia).

LORENÇON.; NUNES, R.V.; POZZA, P.C. POZZA, M.S.S., APPELT, M.D.; SILVA, W.T.M. Utilização de promotores de crescimento para frangos de corte em rações fareladas e peletizadas. Acta Scientiarum Animal Science, v. 29, n.2, p. 151-158, 2007. 
LORENÇON, L; NUNES, R.V; POZZA, P.C; NUNES, C.G.V; APPELT, M.D; BERTICELLI, V. Efeito de diferentes promotores de crescimento sobre o rendimento de carcaças de frangos de corte aos 42 dias de idade. Revista Brasileira de Ciência Avícola,. Campinas, Suplemento 8, p. 102 , 2006a.

LORENÇON, L; NUNES, R.V; POZZA, P.C; POZZA, M.S.S; APPELT, M.D; VENTURI, I. Avaliação de promotores de crescimento no desempenho de frangos de corte de 1 a 42 dias de idade. . Revista Brasileira de Ciência Avícola,. Campinas, Suplemento 8, p. 101, 2006b.

LOPES, K. L. A. M. Suplementação de glutamina em dietas iniciais para frangos de corte. 2008, 12-13f e 30f. Tese (Doutorado em Ciência Animal) - Universidade Federal Goiás/ Escola de Veterinária e Zootecnia, Goiás, 2008.

LUNA, L. G. Manual of histologic staining methods of the armed forces institute of pathology. 3 ed. New York: McGraw-hill, 258p.,1968.

LUQUETTI, B.C.; FARIA FILHO, D.E.; FIGUEIREDO, D. Uso de prebiótico reduz o escore de lesão no intestino delgado de frangos vacinados contra coccidiose. Revista Brasileira de Ciências Avícola, v.7, p.203, 2005

MACARI, M.; FURLAN, R. L. Probióticos. In: Conferência Apinco de Ciência e Tecnologia Avícolas, 2005, Santos, São Paulo. Anais...Campinas: FACTA, 2005, v.1, p. 53-71.

MACARI, M.; FURLAN, R. L.; GONZALES, E. Fisiologia aviária aplicada a frangos de corte. 1. Ed. Jaboticabal: FUNESP/ UNESP, 1994. 29

MACARI, M.; MAIORKA, A. Função gastrointestinal e seu impacto no rendimento avícola. In: CONFERÊNCIA APINCO DE CIÊNCIA E TECNOLOGIA AVÍCOLAS, 2000, Campinas, São Paulo. Anais...Campinas: FACTA, 2000. V.2, p.455-457.

MAIORKA, A. V SIMPÓSIO BRASIL SUL DE AVICULTURA. 2004, Chapecó. Anais...Paraná. Disponível em: www.mercolab.com.br/artigos/AlexMaiorka-Qualidadeintestinal.pdf. Acessado: 30 de Setembro de 2011.

MAIORKA, A; SANTIN, F; SUGETA, S.M; ALMEIDA, J. G; MACARI, M. Utilização de prebióticos, probióticos e simbióticos em dietas para frangos. Revista Brasileira de Ciência Avícola, v. 3, p. 75-81, 2001.

MAIORKA, A. Adaptações digestivas pós-eclosão. In: CONFERÊNCIA APINCO DE CIÊNCIA E TECNOLOGIA AVÍCOLAS, 2001, Santos, São Paulo. Anais...Campinas: FACTA, 2001. v.2, 141151.

MARUTA, K. Probióticos e seus benefícios. In: CONFERÊNCIA DE CIÊNCIA E TECNOLOGIA AVÍCOLAS, 1993, Santos. Anais... Santos: APINCO, 1993. p.203-219.

MEDEIROS, P. T. Produção Avícola: Subsídios na busca de sistemas de alimentação saudáveis, econômicos e de menor impacto ambiental. 2008. 93f. Dissertação (Mestrado). Universidade Federal de Santa Catarina, Centro de Ciências Agrárias. Florianópolis. 2008.

MELLOR, S. Alternatives to antibiotic. Pig Progress, v. 16, n.04, p. 18-21, 2000.

MENTEN, J. F. M.; LODDI, M. M. Probióticos, prebióticos e aditivos fitogênicos na nutrição de aves. In: SIMPOSIO DE NUTRIÇÃO DE AVES E SUÍNOS, 2003, Campinas, São Paulo.

Anais...Campinas: Colegio Brasileiro de Nutrição Animal, 2003. P. 107- 138. 
MENTEN, J.F.M. Probióticos, prebióticos e aditivos fitogênicos na nutrição de aves. In: II SIMPOSIO SOBRE INGREDIENTES NA ALIMENTAÇÃO ANIMAL, 2002, Uberlândia.

Anais...Uberlândia, MG, 2002, p. 251- 276.

MENTEN, J.F.M. Aditivos alternativos na nutricao de aves: probioticos e prebioticos. In: REUNIAO ANUAL DA SOCIEDADE BRASILEIRA DE ZOOTECNIA, 38, 2001, Piracicaba. Anais... Piracicaba, SBZ, 2001, p.141-157.

MURAROLLI, V. D.A. Efeito da prebiótico, probiótico e simbiótico sobre o desempenho, morfologia intestinal e imunidade de frangos de corte. 2008. $101 \mathrm{f}$. Dissertação (Mestrado) Universidade de São Paulo. Faculdade de Medicina Veterinária e Zootecnia. Departamento de Nutrição e Produção Animal, Pirassununga-2008.

NUNES, A.D. Inflência do uso de aditivos alternativos a antimicrobianos sobre o desempenho, morfologia intestinal e imunidade de frangos de corte. 2008. 111f. Dissertação (Mestrado em Medicina Veterinária)- Faculdade de Medicina Veterinária e Zootecnia, Universidade de São Paulo, SP, 2008.

PELICANO, E.R.L.; SOUZA, P.A.; SOUZA, H.B.A. Microscopia eletrônica de varredura da mucosa intestinal de frangos de 21 dias de idade produzidos com probióticos e prebióticos. Revista Brasileira de Ciência Avícola, v.7, p.63, 2005.

PELICANO, E. R. L., SOUZA, P. A., SOUZA, H. B. A. Prebióticos e probióticos na nutrição de aves. Ciência Agr. Saúde. FEA. Andradina, v.2, n.1, p. 59-64, 2002.

QUINTAES, K.D. Alho, nutrição e saúde. Revista NutriWeb, v.3, 2001. Disponível em: www.epub.org.br/nutriweb/n0302/alho. Acesso em: 02 de Outubro de. 2011.

QURESHI, M. A. Interação entre nutrição e o sistema imune e produtividade das aves. In: CONFERÊNCIA APINCO 2002 DE CIÊNCIA E TECNOLOGIA AVÍCOLAS, Campinas. Anais... Campinas: Fundação Apinco de Ciências e Tecnologias Avícolas, 2002, v. 2, p. 243- 251.

RIBEIRO, A. M. L; VOGT, L.K; CANAL, C. W; CARDOSO, M. R.I; LABRES, R.V; STRECK, A. F; BESSA, M.C. Effects of prebiotcs and probiotics on the colonization and immune response of broiler chickens challenged with salmonella enteritidis. Revista Brasileira de Ciência Avícola. V. 9, n. 3, p. 193-200, 2007.

RIBEIRO, A. M; RUDNIK, L. Modulação nutricional e resposta imunológica, In: Simpósio Sobre Manejo e Nutrição de Aves e Suínos e Tecnologia de Produção de Rações, 2002, Campinas.

Anais....Campinas: CBNA, 2002. p. 227-238.

ROSTAGNO, H.S.; ALBINO, L.F.T.; FERES, F.A. et. Al. Utlização de probióticos e prebióticos em aves. In: Prebióticos e probióticos: atualização e prospecção. Viçosa: UFV, 2003. 206p.

SANTOS, G.C. Alternativas ao uso de promotores químicos de crescimento sobre o desempenho e características de carcaças de frangos de corte. 2010. 67f. Dissertação (Mestrado) Faculdade de Ciências Agrárias, Universidade Federal dos Vales do Jequitinhonha e Mucuri. 2010.

SANTOS, E.C; TEIXEIRA, A. S; DIAS, E. S. Efeitos dos aditivos beneficiadores de crescimento sobre o desempenho de frangos de corte. 39a Reunião da Sociedade Brasileira de Zootecnia. Anais....Recife, 2002, Nutição de não ruminantes, SBZ 590, 2002. CD-ROM. 
SANTIN, E; MAIORKA, A; MACARI, M; SANCHEZ, J.C; OKADA, T. M; MYOSAKA, A. M. Performance and intestinal mucosa development of broiler chickens fed diets containing Saccharomyces cerevisae cell wall. Journal Applied Poultry Science Research,, v. 10, p. 236-244, 2001.

SCHWARZ, K.K. Substituição de antimicrobianos por probióticos e prebióticos na alimentação de frangos de corte. 2002. 46 f. Dissertação ( Mestrado em Ciências Veterinária) Universidade Federal do Paraná, Curitiba, 2002.

SILVA, C. R. Uso de probióticos em rações de frangos de corte: Desempenho, digestibilidade e energia metabolizável. 2008. 64f. Dissertação (Mestrado) Universidade Federal de Viçosa. MG, 2008.

SILVA, W.I.M; NUNES, R.V; POZZA, P. C; NUNES, C.G.V; VENTURI, I; APPELT, M.D. Utilização de probiótico, prebiótico e simbiótico na alimentação de pintos de corte de 1 a 21 dias de idade. . Revista Brasileira de Ciência Avícola,. Campinas, Suplemento 8, p. 135, 2006.

SILVA, E.N. 2004. A polêmica da resistência a antibióticos em aves. Disponível em: www.abrappa.org.br. Acessado: 02 de Outubro de 2011.

SILVA, L.P.; NORNBERG, J.L. Prebioticos na nutricao de não-ruminantes.. Cienc. Rural, Santa Maria, v.33, n.4, p. 55-65, 2003.

SILVA, E.N. Probióticos e prebióticos na alimentação de aves. In: CONFERÊNCIA APINCO DE CIÊNCIA E TECNOLOGIA AVÍCOLAS, 2000, Campinas, São Paulo. Anais...Campinas: FACTA, 2000. V.2, p. 241-251.

SIMÕES, C. M. O.; SPITZER, V. Óleos voláteis. In: SIMÕES, C.M.O. et al. Farmacognosia: da planta ao medicamento. Porto Alegre: UFRGS, 1999. Cap.18, p.387-416. 1999.

SOUZA, J. D; FERREIRA, V. M; OLIVEIRAS, D; AICHINGER, A.; MACHADO, L. C. Revista eletrônica Nutritime, v.3, n.6, p. 368-373, novembro/dezembro, 2006.

SHI, X.H.; LI, S.Z.; LIU, Z.P. A trial on the use of garlic as a feed additive for meat chickens. Poultry Husbandry and Disease Control, v.10, p.19-20, 1999.

STRINGHINI, J.H.; MOGYCA, N.S.; ANDRADE, M.A. et al. Efeito da qualidade do milho no desempenho de frangos de corte. Revista Brasileira de Zootecnia, v.29, n.1, p.191-198, 2000.

TOLEDO, R.S.; ROCHA, A. G.; FARIAS, L. C. Uso de aditivos na produção avícola da teoria a prática. In: X SIMPÓSIO BRASIL SUL DE AVICULTURA E I BRASIL SUL POULTRY FAIR, 2009, Chapecó, SC- Brasil. Anais... Chapecó, Santa Catarina, 2009.

TOLEDO, G. S. P.; COSTA, P.T.C.; SILVA, L. P. et al. Desempenho de frangos de corte alimentados com dietas contendo antibióticos e/ou fitoterápico como promotores, adicionados isoladamente ou associados. Ciência Rural, Santa Maria, v. 37, n.6, p. 1760-1764, Nov-dez, 2007.

TOURNUT, J. R. Probiotics. In: Reunião da Sociedade Brasileira de Zootecnia. 35. 1998, Botucatu. Anais... Botucatu: SBZ, 1998, p. 179-1999. 
WANG, R.; LI, D.; BOURNE, S. Can 2000 years of herbal medicine history help us solve problem in year 2000?. In: ALLTECH'S ANNUAL SYMPOSIUM, Nottingham, Anais...

Nottingghan: ALLTECH, p. 168-184, 1998.

WOLKE, LF.; FLEMING, J.S.; MIRA, R.T. et al. Utilização do probiótico Bacillus natto como promotor de crescimento na alimentação de frangos de corte. In: REUNIÃO ANUAL DA SOCIEDADE BRASILEIRA DE ZOOTECNIA, 33, 1996, Fortaleza. Anais... Fortaleza: SBZ, 1996. p.36-38.

YANG, Y; IJI, P. A; CHOCT, M. Effects of different dietrary levels of mannanoligosaccharide on growth performance and gut development of broiler chickens. Asian- Australasian Journal of Journal Animal Sciences, v. 20, n. 7, p. 1084-1091, 2007. 